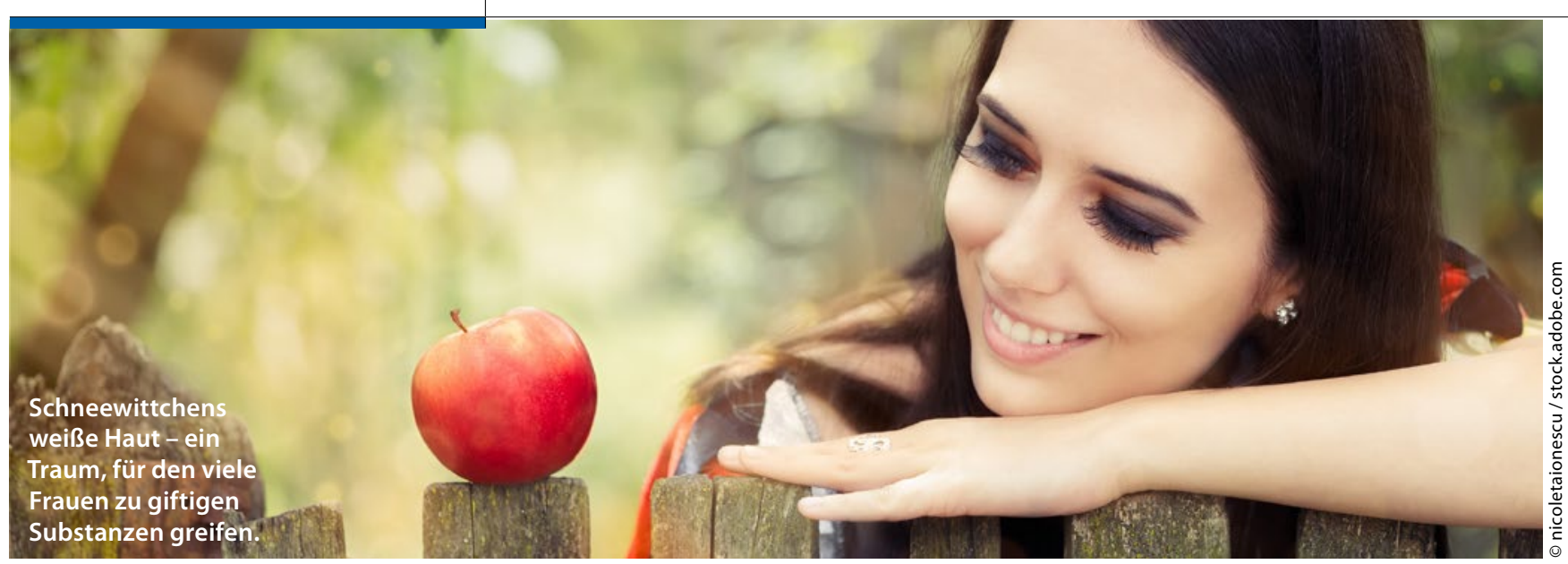

\title{
Hautaufhellung
}

\section{Schneewittchen in Indien}

\author{
Die südafrikanische Sprache isiXhosa bezeichnet die Hautaufhellung \\ als „ukutsheyisa", übersetzt "nach Schönheit jagen“. In Afrika wie in \\ Indien, Gebieten mit den vielfältigsten Hautschattierungen, gilt: Je \\ heller die Haut, desto größer das soziale Ansehen, wahrscheinlicher \\ ein erfolgreicher Lebensweg, attraktiver die Person als möglicher \\ (Ehe-)Partner. Menschen dunklerer Hautfarbe hingegen sind oft \\ sozialer Abwertung und Schikanen ausgesetzt.
}

$\mathrm{F}$ rauen treffen soziale Benachteiligungen besonders hart. Vielerorts hängt in den genannten Regionen ihre gesellschaftliche Akzeptanz, oft das bloße Überleben von der Ehe ab. Die Heiratschancen aber stehen für Frauen mit dunklerer Hautfarbe deutlich schlechter. Indische Mütter etwa suchen mittels Anzeigen für ihre Söhne nach Frauen, deren Hautfarbe ,wheatish", also "weizenfarben" sein sollte. Auch Karrieren als Filmstar oder Model sind nur mit hellem Teint möglich.

\section{Vergiftete Schönheit}

Um ihre Chancen zu verbessern, helfen viele Frauen nach. Make-Up, das Meiden der Sonne oder die Anwendung natürlicher Substanzen wie Honig, Zitronensaft, Eigelb oder Rosenwasser sind dabei die harmlosesten Varianten.

Häufig kommen von der Pharmaindustrie erzeugte Cremes zum Einsatz, die ein Aufhellen der Haut versprechen. Je nach Preis sind diese Mittel mehr oder weniger effektiv - und bergen mehr oder weniger gesundheitliche Risiken. Insbesondere preiswerte Cremes sind mit nachweislich gesundheitsschädlichen Substanzen wie Bleiweiß, Hydrochinon, Steroide, Kortison oder Quecksilber versetzt.

Obwohl solche Mittel zunächst meist die gewünschte Wirkung zeigen, können sie langfristig irreversiblen Schäden hervorrufen: Der Wirkstoff Hydrochinon etwa, der in Farben und als Fotoentwickler Verwendung findet, reduziert den natürlichen Melanin-Gehalt der Haut und macht sie empfindlicher gegenüber UV-Licht. Oft kommt es bei den betroffenen Hautpartien auch zur Hyperpigmentierung. Auch Leber- und Nierenversagen oder Krebs sind häufige Folgeerscheinungen. Doch diese Risiken werden wissentlich in Kauf genommen.

Laut Weltgesundheitsorganisation (WHO) verwendeten $77 \%$ der nigerianischen Frauen im Jahr 2013 Mittel zur Hautbleichung, in Togo waren es $59 \%$.
An der Elfenbeinküste wurden in den späten 1960er-Jahren Hautaufhellungsprodukte - nach Seife, Tee und Dosenmilch - zur vierthäufigsten Haushaltsware.

Industrie und Handel kommt der Konsumbedarf sehr gelegen, Werbung und (soziale) Medien fördern ein entsprechendes Schönheitsideal. Und stets werden neue Märkte erschlossen: Vor wenigen Jahren warb ein indischer Werbespot für ein Produkt, das die Aufhellung der Vagina versprach.

\section{Frage des Selbstbildes}

Doch auch Männer werden immer empfänglicher für die Idee der Hautbleichung. Der bekannteste indische Schauspieler, Shah Rukh Khan, warb für eine Creme zur Hautaufhellung. Eine Protestnote von 15.000 Unterzeichnern blieb unbeantwortet.

Zwar protestieren Frauengruppen in Indien mittlerweile gegen „entwürdigende" Werbespots für Hautaufheller. Zwar ist die Verwendung von Hydrochinon in frei erhältlichen Kosmetika mittlerweile verboten. Doch trotz Protesten finden Werbespots nach wie vor ihre Zielgruppen. Und auch Schmuggelware findet dankbare Abnehmer. Mindestens ebenso wichtig wie Gesetzgebungen und deren Kontrolle - ist daher eine Änderung des Selbstbildes. Auch hierbei können (soziale) Medien eine entscheidende Rolle spielen. 